\title{
The Influence of Trains on the Seismic Response of Simply-Supported Beam Bridges with Different Pier Heights Expressed through a Safety Factor
}

\section{Lizhong Jiang}

Central South University

\section{Kang Peng}

Central South University

Jian Yu

Central South University

Wangbao Zhou ( $\square$ zhouwangbao@163.com )

Central South University https://orcid.org/0000-0003-3338-4971

\section{Yongjian Zuo}

Central South University

\section{Research Article}

Keywords: random earthquake, high-speed railway, simply-supported girder bridge, high-speed train, seismic response

Posted Date: June 29th, 2021

DOl: https://doi.org/10.21203/rs.3.rs-656142/v1

License: (c) (i) This work is licensed under a Creative Commons Attribution 4.0 International License. Read Full License 


\title{
The influence of trains on the seismic response of simply-supported beam bridges with different pier heights expressed through a safety factor
}

\author{
Lizhong Jiang ${ }^{1,2 \#}$, Kang Peng ${ }^{1,2 \#}$, Jian $\mathrm{Yu}^{1,2 \#}$, Wangbao Zhou ${ }^{1,2 *}$, Yongjian Zuo ${ }^{1,2}$ \\ 1. School of Civil Engineering , Central South University , Changsha 410075 , China; \\ 2. National Engineering Laboratory for High Speed Railway Construction, Changsha 410075 , China
}

\begin{abstract}
With the extension of high-speed railways to high-intensity earthquake regions, it is impossible to avoid structural vibrations due to the joint action of trains and earthquakes. Therefore, it is of great significance to study the influence trains on bridge structures exposed to earthquakes. In this paper, a coupled finite element analysis model of a high-speed railway vehicle-bridge was established by considering a simply-supported beam bridge with the China Railway Track System (CRTS) II plate and the CRH2C high-speed train. The correctness of the model was experimentally verified. By considering the ground motion randomness, the influence of the train on the response of the bridge structure exposed to an earthquake was analyzed. Also, the influence level of the running train on the seismic response of bridge structures with different pier heights was studied. The results revealed that the train dynamic effect significantly reduced seismic responses of piers and supports, and that the effect itself decreased with the pier height increase. Furthermore, the dynamic effect of the train increased the seismic response of the track structure, while the bridge pier height had little influence on the dynamic efficiency of the track structure. For different pier heights, the probability distribution model of the train dynamic effect for the track-bridge system seismic response was considered as the normal distribution. This indicated that the seismic response of the track-bridge system under vehicle condition could be simplified as the product of the seismic response and safety factor under no vehicle condition.
\end{abstract}

Keywords: random earthquake; high-speed railway; simply-supported girder bridge; high-speed train; seismic response

\section{Introduction}

China has a vast territory, and up to the end of 2019 the railway mileage in operation has reached 139,000 km, among which the high-speed railway (HSR) mileage (constructed all over the country) has exceeded 35,000 km (The State Council Information Office of the People's Republic of China 2020). While providing fast and convenient travel, higher safety and comfort requirements have been put forward (Su et al. 2019). Due to the excessively high bridge occupancy ratio and the increasing train running density of the HSR, the probability of a train running during an earthquake is constantly increasing (Guo et al. 2020). In order to ensure the bridge structure safety, it is of great theoretical significance and practical engineering value to study the influence of high-speed trains on the seismic response of bridge systems.

A reasonable and applicable vehicle-bridge coupled model represents the basis for studying the seismic response of a trainbridge system. As early as 1850, Galton (1850) simplified a train load to a moving concentrated force, established a vehicle-bridge theoretical model, and obtained analytical results. Based on the obtained findings, Timoshenko (1922) proposed the vertical vibration equation of a bridge. Fryba (1996) improved it and established a 4 degree-of-freedom (DOF) vehicle model, by taking into account bridge viscous resistance characteristics and factors of track irregularity. Yang et al. (1997) simplified a vehicle into a mass block combination, and the vehicle mass was distributed to the car body and bogie. In order to evaluate the dynamic interaction

\footnotetext{
\# The authors contribute equally to this paper.

\# The authors contribute equally to this paper.

\# The authors contribute equally to this paper.

* Corresponding author, Ph.D., E-mail: zhouwangbao@163.com; ORCID: 0000-0003-3338- 4971 
between a bridge and a train under an earthquake, He et al. (2011) provided a simplified vehicle-bridge coupling model. The vehiclebridge coupling relationship of the model was established by assuming that the bridge and the vehicle were always closely attached and the degrees of freedom were coupled to each other. This method greatly improved the computational efficiency and was recognized by many scholars (Kim and Kawatani 2006; Kim et al. 2011; Yu et al. 2021, 2020).

At present, most studies are considering specific earthquake motions, and there is a lack of analyses of the ground motion randomness influence on structures. Mackie et al. (2001) found that the ground motion randomness has a great influence on structural damage, which cannot be ignored. Long duration earthquakes significantly reduce seismic hysteresis performance, aggravate the degradation of structural strength and stiffness, and seriously endanger structural safety (Chandramohan et al. 2016; Hancock and Bommer 2006; Mackie and Stojadinović 2001; Raghunandan and Liel 2013). He et al. (2011) also pointed out that the difference in the influence of different types of ground motions may be significant, and that the results obtained on the basis of a single ground motion lack the accuracy and rationality.

Lately, the influence factors and response mechanism of a train-bridge system under an earthquake receive more and more attention. Liu et al. (2018) compared the dynamic characteristics of a single bridge model and a vehicle-bridge coupled model, and found that there were significant differences in natural vibration characteristics and structural responses of the two models. In order to ensure the traffic safety of high-speed trains, the coupled model should be used for the seismic analysis. Yang and Wu (2002) derived the motion equation of a train-track-bridge system and studied the dynamic stability of the train running on the bridge under the influence of ground motion. Du et al. (2012) found that ignoring uniform ground motions in the lateral acceleration response of trains may underestimate the seismic response. Zeng et al. (2015) studied random vibration characteristics of bridges and trains, and showed that the seismic amplification degree of bridge and train transverse accelerations is usually much larger than that of vertical accelerations. Kim et al. $(2006,2011)$ found that a dynamic monorail system acted as a damper on the monorail bridge, which indicated that the existing method of treating a train as an additional mass results in conservative results, and that the response of a bridge pier under the combined action of horizontal and vertical earthquakes was larger than that under the action of only horizontal ones. Therefore, both horizontal and vertical earthquakes should be considered when applying seismic loads. Chen et al. (2018) considered the influence of pier settlement on the dynamic response of a vehicle-bridge coupling system, and the results showed that vertical accelerations of the car body were more sensitive to pier settlement, and that the influence of the train load on track stress was far less than that of pier settlement. Xia et al. (2008) studied the influence of transverse vibrations of multi-span bridges, and the results showed that high pier bridges were significantly affected by transverse earthquakes. Although the study of Yu et al. $(2021,2020)$ considered the influence mechanism of trains on the structural response for earthquakes with different peak ground accelerations (PGAs), it was still insufficient for practical engineering applications. It was difficult to provide specific simplified parameters for different structural forms, as well as to generate practical and effective guidelines. In addition, the analysis and calculation of vehicle-rail-bridge coupling is very complex, and the knowledge on the specific influence level of trains can significantly reduce the workload of designers and improve the design efficiency.

In this paper the CRH2C high-speed train and the China Railway Track System (CRTS) II plate-type ballastless track simplysupported beam bridge were used as prototypes to establish a vehicle-bridge coupled model, and to carry out an experimental comparison. By considering the randomness of ground motions, the influence mechanism of the high-speed train on different pierrail structures exposed to earthquakes was studied, and the parameter simplification method for bridges with different pier heights under vehicle condition (a train running on a bridge) was proposed. The research results are expected to be helpful for the seismic 
design and analysis of the HSR bridges.

\section{Finite element model of the HSR train-track-bridge system}

\subsection{Finite element model}

A high-speed railway three-span simply-supported beam bridge with the CRTS II slab ballastless track system in the 8 degree earthquake fortification zone and the $\mathrm{CRH} 2 \mathrm{C}$ type high-speed railway train were selected for analysis. Abutments, friction plates, and subgrade sections were arranged at both ends of the simply-supported beam bridge from inside to outside, as shown in Fig. 1. The main girder was $32.5 \mathrm{~m}$ standard prestressed concrete box girder with a gap of $0.1 \mathrm{~m}$. Anti-falling girders were set on both sides with the interval of $0.2 \mathrm{~m}$. The bearing was an aseismic basin-type rubber bearing, with the vertical bearing capacity of $5,000 \mathrm{kN}$ (Fig. 2). The piers were (1) low piers with round end solid constant section (pier height 4 12 m), (2) median piers with round end solid variable section (pier height 16 24 m), and (3) high piers with round end hollow variable section (pier height $28 \sim 40 \mathrm{~m}$ ). The sizes of piers are shown in Table 1T and Fig. 2, where the pier slope is the ratio of the pier height to its expansion length. The pier cross-section size was defined with L and B, representing transverse and longitudinal dimensions (respectively), and with the hollow pier wall thickness (only for high piers).

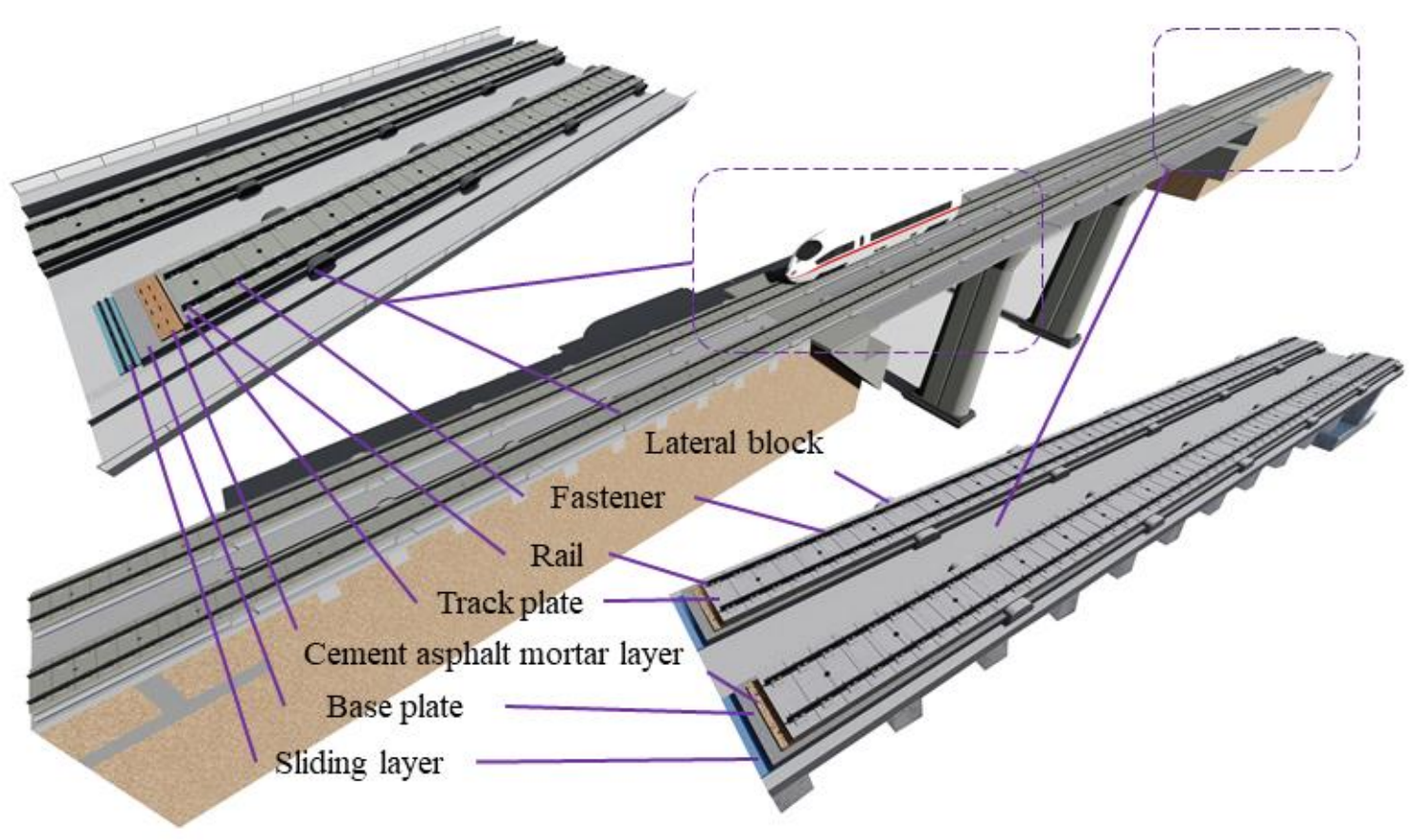

Fig. 1 Structural layout of the HSR simply-supported bridges and track-bridge system

The track structure comprises a base plate with the cross-section size of $2.95 \times 0.19 \mathrm{~m}$, a track plate with the cross-section size of $2.55 \times 0.2 \mathrm{~m}$ and the CHN60 type rail. The thickness of the sliding layer laid between the main beam and the base plate was $6 \mathrm{~mm}$. The thickness of the cement asphalt (CA) mortar layer laid between the base plate and the track plate was $3 \mathrm{~cm}$. Type WJ-8C fastener was installed on the rail plate and rail. The shear gear groove was arranged on the surface of the beam body above the fixed support, the shear reinforcement was arranged between the track plate and base plate on both sides of the beam seam, and the lateral retaining 
block of $5.74 \mathrm{~m}$ was arranged on the bridge deck and friction plate. The HSR was composed of 2 power cars and 14 passenger cars, with the train parameters shown in Table 2.
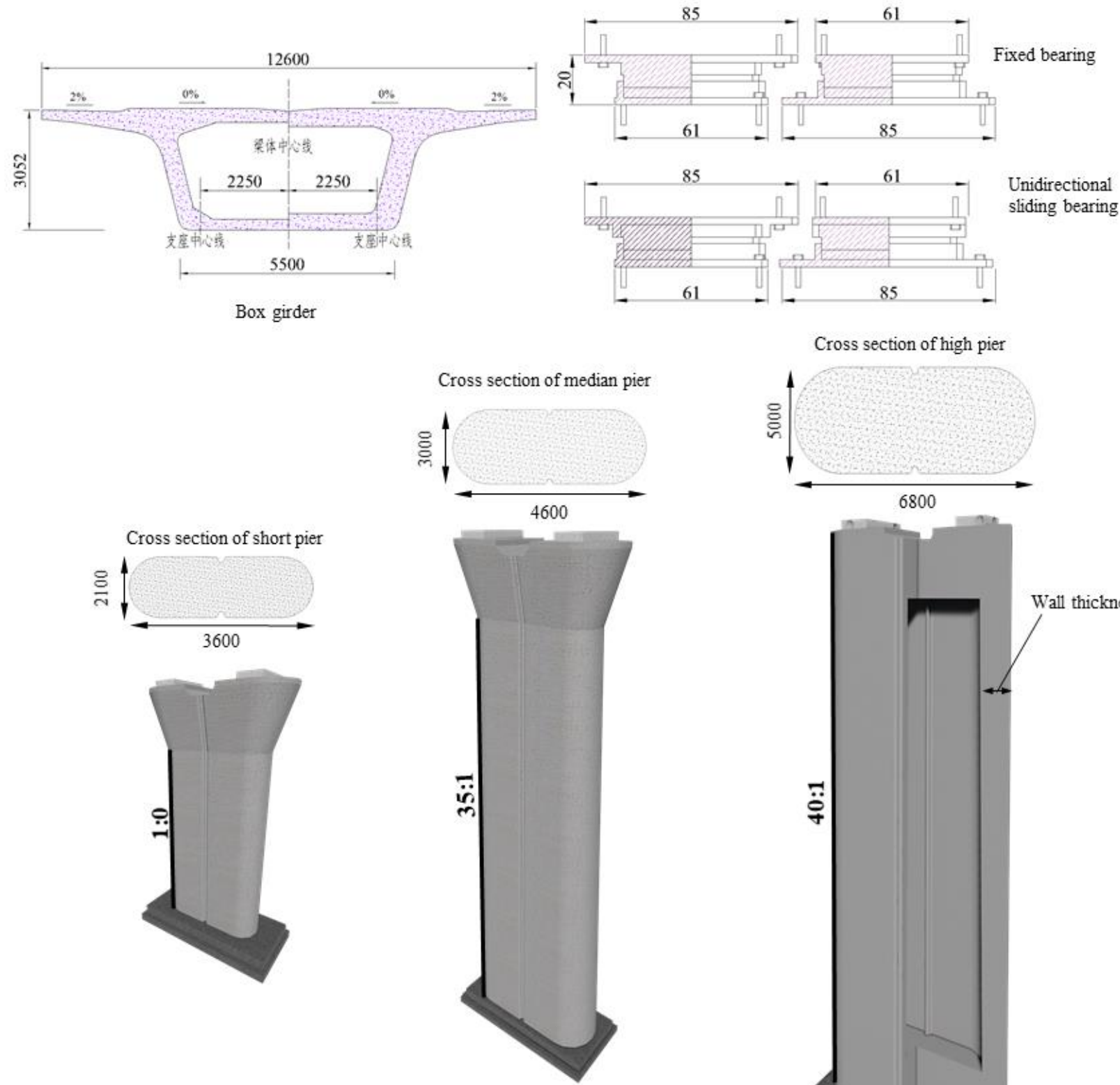

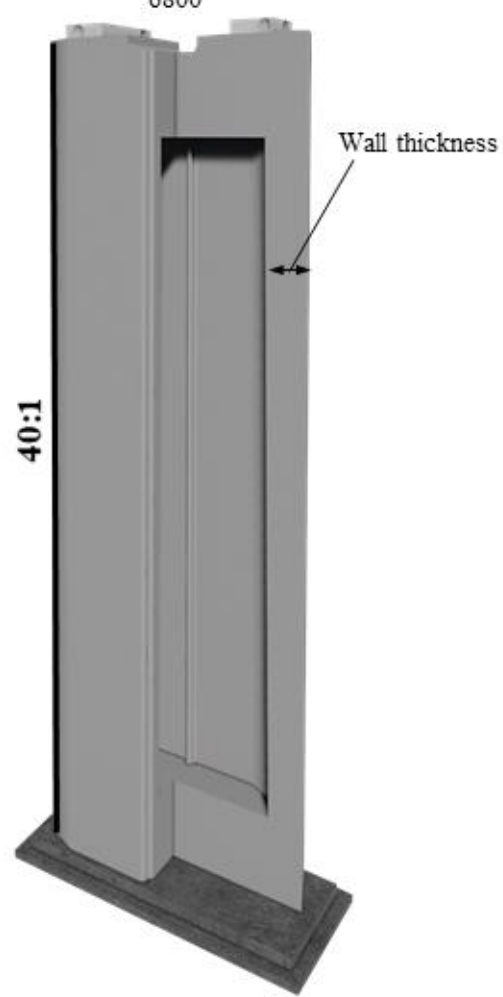

Fig. 2 Structural properties of the HSR system (dimensions in $\mathrm{mm}$ ) 
Table 1 Parameters of the considered piers

\begin{tabular}{lllll}
\hline Pier type & Height $(\mathrm{m})$ & Slope & Pier size $(\mathrm{mm})$ & Wall thickness (mm) \\
\hline \multirow{3}{*}{ Short } & 4 & $1: 0$ & $2100 / 3600$ & - \\
& 8 & & & \\
Median & 12 & $35: 1$ & $3000 / 4600$ & \\
& 16 & & & 70 \\
& 20 & & & \\
High & 24 & $40: 1$ & $5000 / 6800$ & \\
\end{tabular}

Table 2 Main parameters of the CRH2C train

\begin{tabular}{ccc}
\hline Property & Value & Unit \\
\hline Primary (per axle box) \& secondary (per side of bogie) suspension vertical damping coefficient & $5 \& 39.87$ & $\mathrm{kN} \cdot \mathrm{s} / \mathrm{m}$ \\
Primary (per axle box) \& secondary (per side of bogie) suspension transverse damping coefficient & $0 \& 58.86$ & $\mathrm{kN} \cdot \mathrm{s} / \mathrm{m}$ \\
Primary (per axle box) \& secondary (per side of bogie) suspension longitudinal damping coefficient & $0 \& 5.06$ & $\mathrm{kN} \cdot \mathrm{s} / \mathrm{m}$ \\
Primary (per axle box) \& secondary (per side of bogie) suspension vertical stiffness & $1,176 \& 190$ & $\mathrm{kN} / \mathrm{m}$ \\
Primary (per axle box) \& secondary (per side of bogie) suspension transverse stiffness & $6,470 \& 160$ & $\mathrm{kN} / \mathrm{m}$ \\
Primary (per axle box) \& secondary (per side of bogie) suspension longitudinal stiffness & $14,680 \& 160 \quad \mathrm{kN} / \mathrm{m}$ & 1,800 \\
Wheelset mass & 3,300 & $\mathrm{~kg}$ \\
Bogie frame mass & Train body mass & 35,000 \\
Bogie wheelbase & 17.5 & $\mathrm{~kg}$ \\
Distance between bogie centers & $\mathrm{m}$ \\
\hline
\end{tabular}

ANSYS finite element software was used to establish the train-track-bridge system. In the track-bridge subsystem (Fig. 3) the friction plate, main beam, bottom plate, track plate and rail were simulated by the Timoshenko beam element BEAM189 with the length of which $3.25 \mathrm{~m}$. The same element was also used to simulate piers with sizes determined according to Fig. 2 and Table 1. For the short pier with constant section, three models with heights of $4 \sim 12 \mathrm{~m}$ were established at $4 \mathrm{~m}$ intervals. For the median pier with variable section, three models with heights of 16 24 m were established at $4 \mathrm{~m}$ intervals. Finally, for the high pier with variable section, four models with heights of $28 \sim 40 \mathrm{~m}$ were established at $4 \mathrm{~m}$ intervals. The nonlinear spring elements CONBIME39 and CONBIME40 were used to simulate the support, anti-fall beam, shear gear groove, sliding layer, shear reinforcement, CA mortar layer, lateral retaining fastener, and fastener of the track-bridge structure. The sliding layer, CA mortar layer and coupler were arranged according to the unit length. Table 3 shows the parameters of force-displacement curves adopted for the springs, where $F x$ $\& F y$ and $D x \& D y$ represent the yield forces and yield displacements in the transverse and longitudinal directions, respectively. 


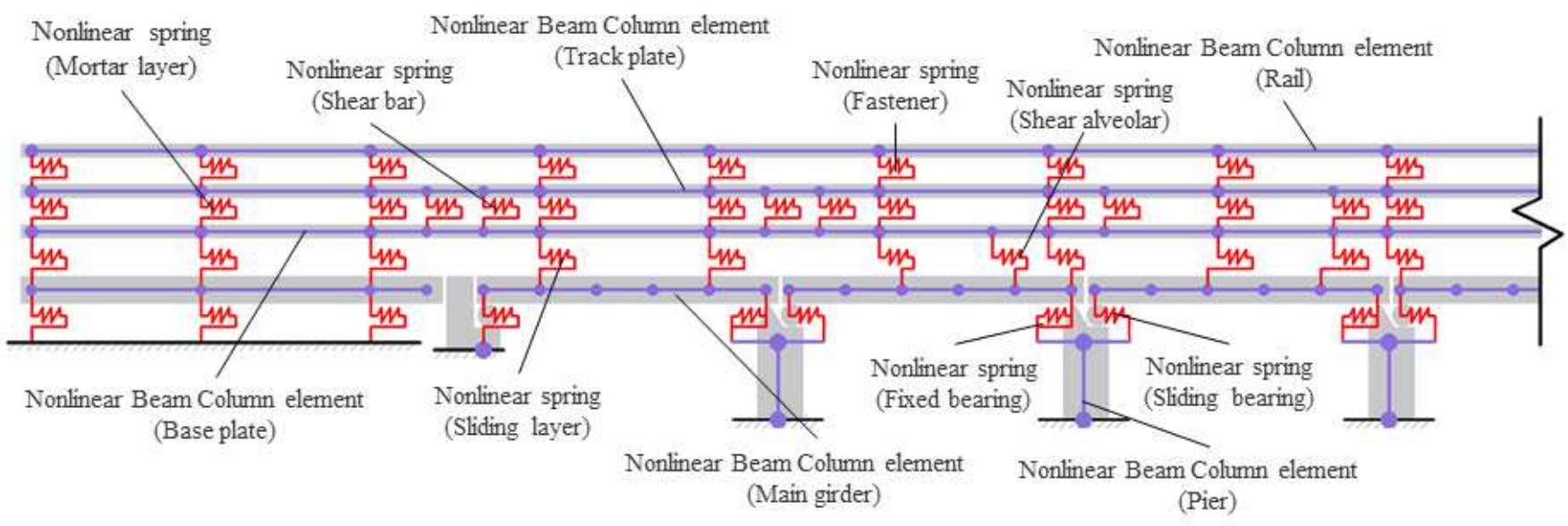

Fig. 3 Finite element model of the HSR three-span simply-supported track-bridge system

Table 3 The parameters of force-displacement curves of the spring elements

\begin{tabular}{cccccc}
\hline Force-displacement curve & Component & $F y / \mathrm{kN}$ & $F x / \mathrm{kN}$ & $D y / \mathrm{mm}$ & $D x / \mathrm{mm}$ \\
\hline & Fastener & 24 & 9 & 2.00 & 2.00 \\
& CA mortar layer & 42 & 42 & 0.50 & 0.50 \\
& Sliding bearing & 100 & 100 & 2.00 & 2.00 \\
& Fixed bearing & 1,000 & 1,000 & 2.00 & 2.00 \\
& Lateral block & 453 & 0 & 2.00 & 0.00 \\
& Shear reinforcement & 23 & 23 & 0.08 & 0.08 \\
& Shear groove & 1,465 & 1,465 & 0.12 & 0.12 \\
\hline
\end{tabular}

As shown in Fig. 4, in the train subsystem eight mass springs whose center line was located at the wheelset were used to simulate the car. The train mass and the stiffness and damping of the suspension system were evenly distributed among the car body, bogie and wheelset, where $M_{\mathrm{v}}$ represents the train body mass, $M_{\mathrm{b}}$ represents the bogie mass and $M_{\mathrm{w}}$ represents the wheelset mass. Furthermore, $K_{1}$ represents the stiffness of the first spring, $K_{2}$ represents the stiffness of the second spring, $C_{1}$ represents one series spring damping, and $C_{2}$ represents two series spring damping. The car was connected to the rail by rigid bars, which satisfied the following corresponding equivalence relations (Chen et al. 2014): $M_{\mathrm{v}}=8 m_{\mathrm{v}}, M_{\mathrm{b}}=4 m_{\mathrm{b}}, M_{\mathrm{w}}=2 m_{\mathrm{w}}, K_{1}=k_{1}, K_{2}=2 k_{2}, C_{1}=c_{1}, C_{2}=$ $2 c_{2}$. 


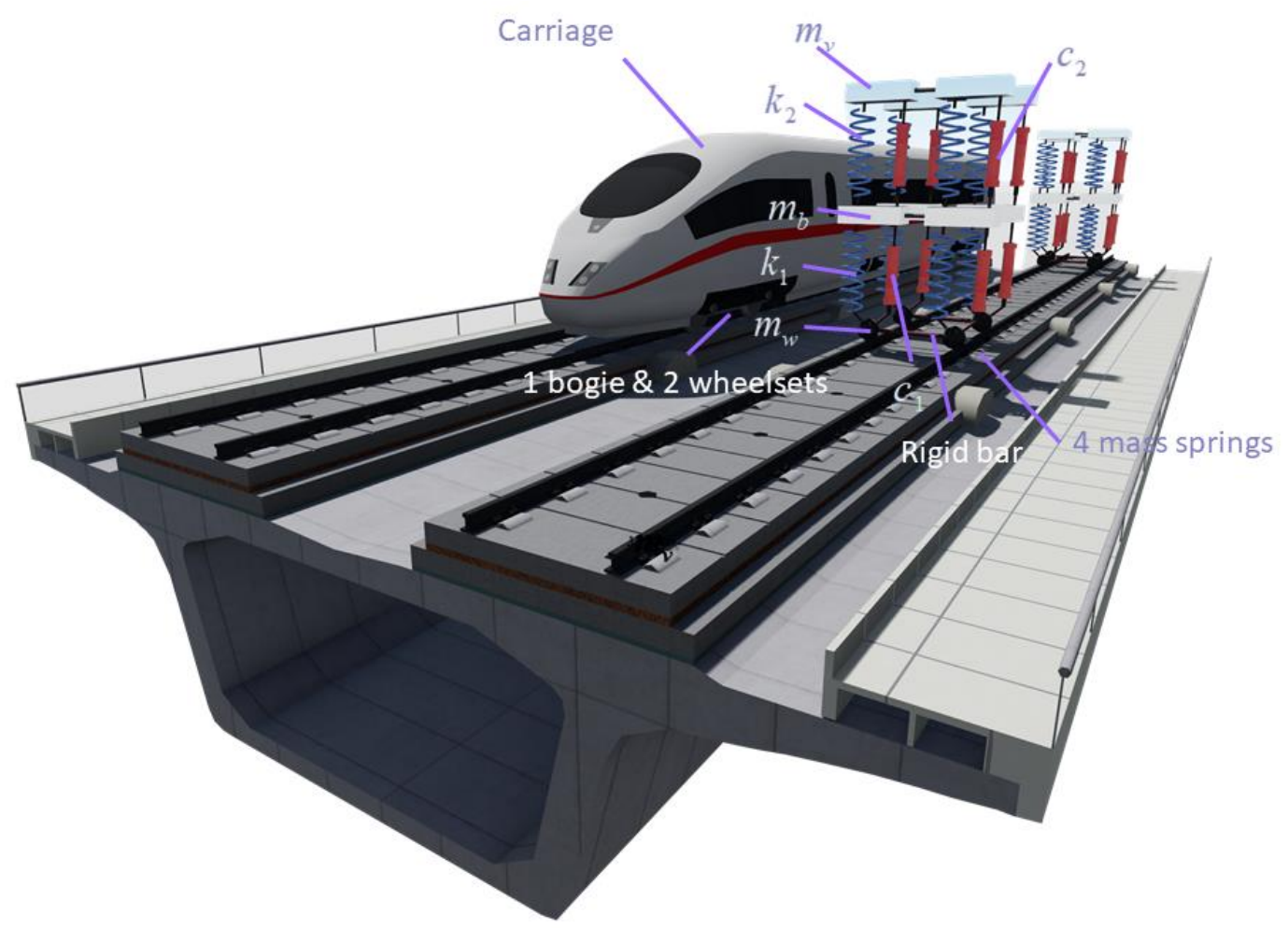

Fig. 4 Train model and equivalent mass springs

In this experiment the vehicle-rail coupling was achieved by assuming the same horizontal and vertical degrees of freedom for the wheel and the track. This approach provided sufficient test accuracy and also increased the computational efficiency (Tanabe et al. 2011, 2016; Yu et al. 2020, 2021). The coupling of the two subsystems (the train subsystem and track-bridge subsystem) was accomplished by using transient analysis in ANSYS, with the following steps: ground motion was imposed while the train began to move on the bridge. At each time step, the wheelset location was estimated and vertical and lateral freedom degrees of the wheelset and rail were coupled. Transient analysis was used to analyze the seismic response of bridge structures under the seismic acceleration. After the calculation was completed all coupling was removed, and the above process was repeated for the next step of analysis.

\subsection{Comparison between the finite element analysis and shaking table test}

The results obtained from the finite element model were compared with the shaking table test results obtained by Yu et al. (2021) to verify the model validity and correctness. The whole experiment included five parts: shaking table system, scaled model, train acceleration and deceleration device, transition device and measuring system, as shown in Fig. 5. The shaking table system was composed of four $4 \mathrm{~m} \times 4 \mathrm{~m}$ shaking tables, one fixed and three movable. The maximum length of the shaking table working area system was $55 \mathrm{~m}$, which met the test requirements.

The test setup is schematically shown in Fig. 7. The train model was customized according to the similarity ratio (details are provided in Fig. 6), which was also used for the bridge model selection. The VIC-3D high-speed camera system was arranged between girders \#5 and \#6 for observation.

The test process was as follows. The train was installed in the acceleration section. At the beginning of the experiment, the train was accelerated to the trial speed of $5 \mathrm{~m} / \mathrm{s}$. After passing the transition device, the train entered the test section, the seismic wave was applied (Fig. 6), and the shaking table vibrated until the train entered the deceleration area. The experimentally obtained 
records were compared with the calculation results of the corresponding area by using the finite element model, as shown in Fig. 8 and Table 4. It can be seen that the acceleration values and lateral displacements were in good agreement, with an error within $17 \%$, which indicates that the finite element model accurately simulated the coupled vibration of the train-track-bridge system under the earthquake action.

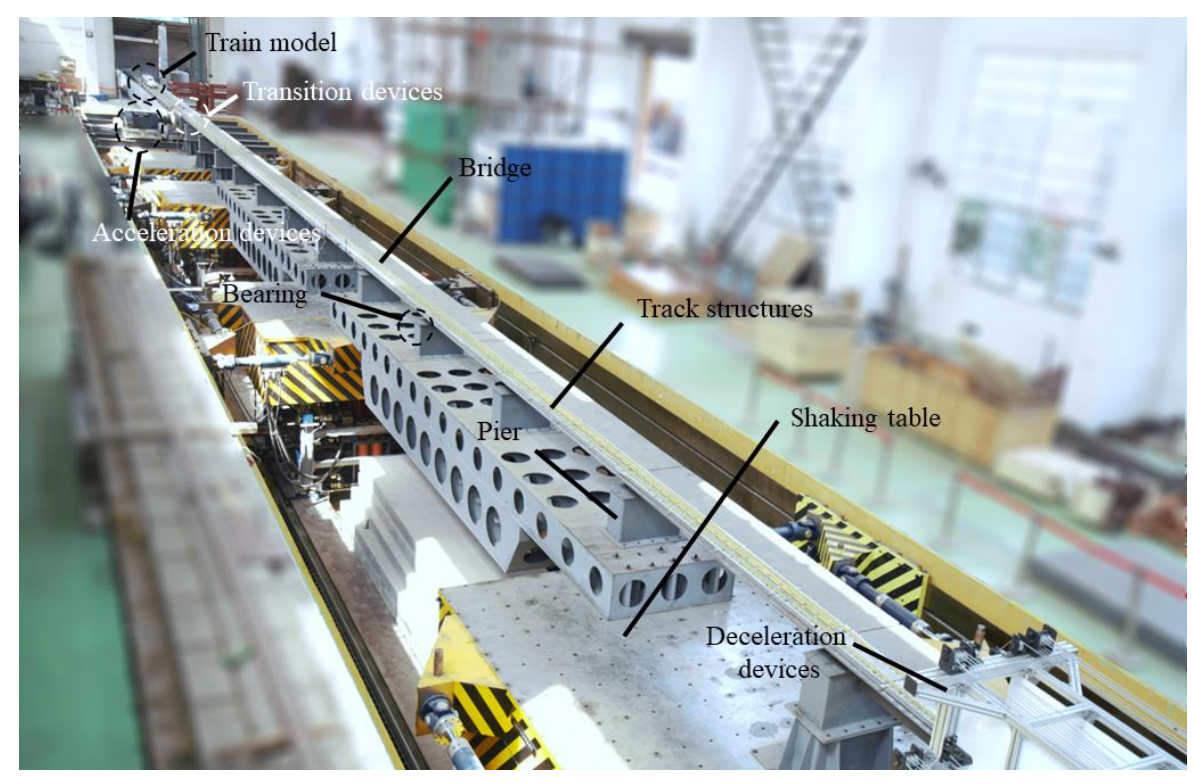

Fig. 5 The shaking table system and the scaled train-track-bridge model (Yu et al. 2021)

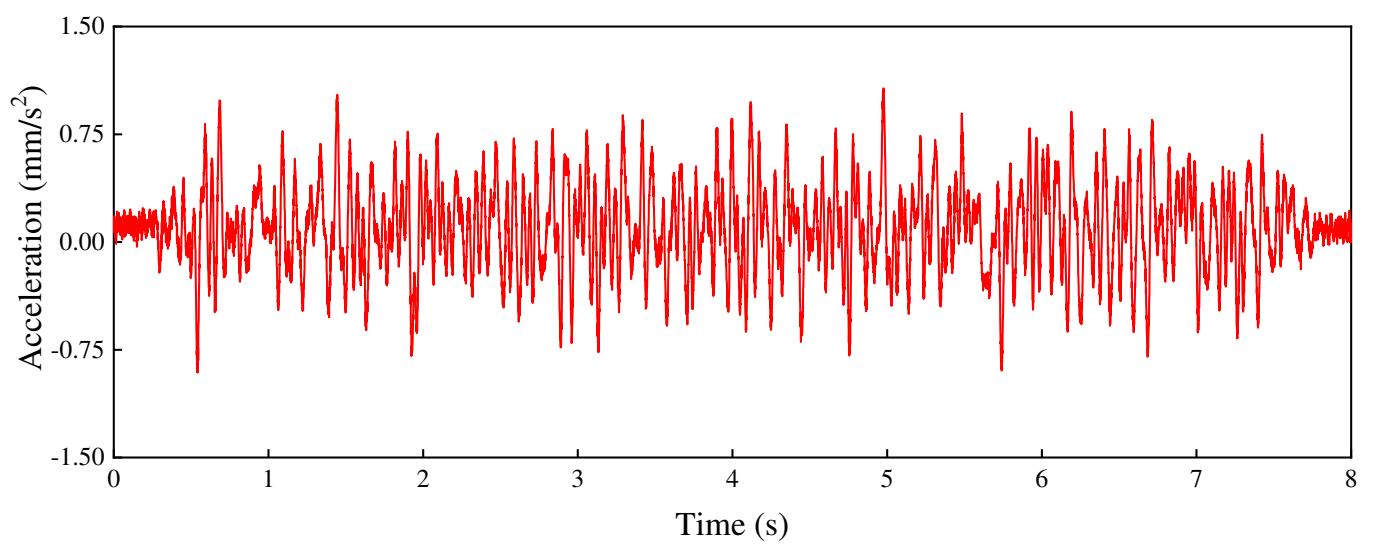

Fig. 6 Lateral acceleration time history of the seismic input 


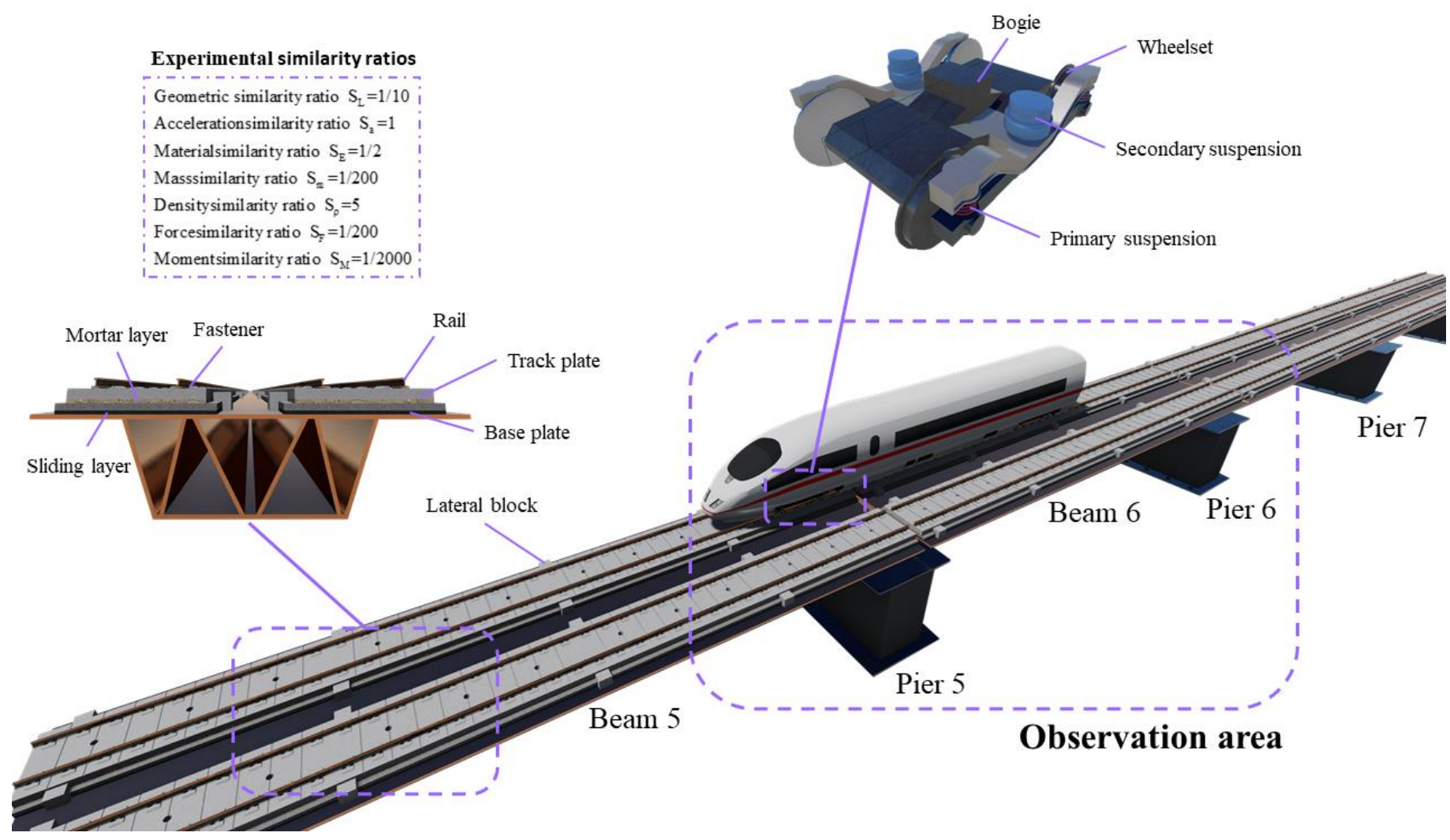

Fig. 7 Schematic test layout and observation area

Table 4 The maximum deformation of components at the \#6 box girder sliding end

\begin{tabular}{llll}
\hline Component & Test value $(\mathrm{mm})$ & Numerical simulation $(\mathrm{mm})$ & Error $(\%)$ \\
\hline Deformation of the fixed bearing & 0.27 & 0.30 & $11 \%$ \\
Deformation of the sliding bearing & 0.28 & 0.30 & $9 \%$ \\
Deformation of the sliding layer & 0.31 & 0.26 & $16 \%$ \\
Deformation of the mortar layer & 0.24 & 0.20 & $17 \%$ \\
Deformation of the rail fastener & 0.32 & 0.28 & $13 \%$ \\
\hline
\end{tabular}

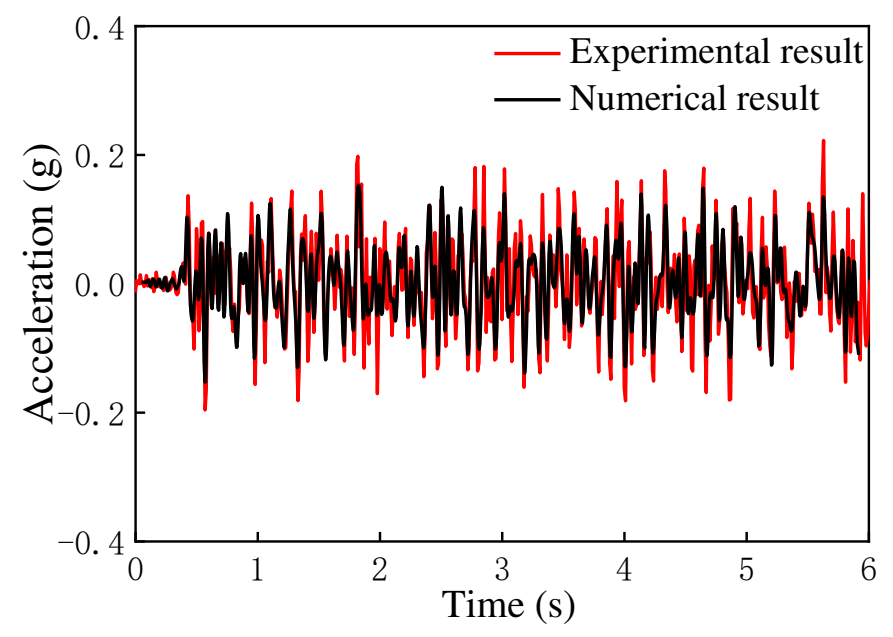

(a) Acceleration at the \#5 pier top

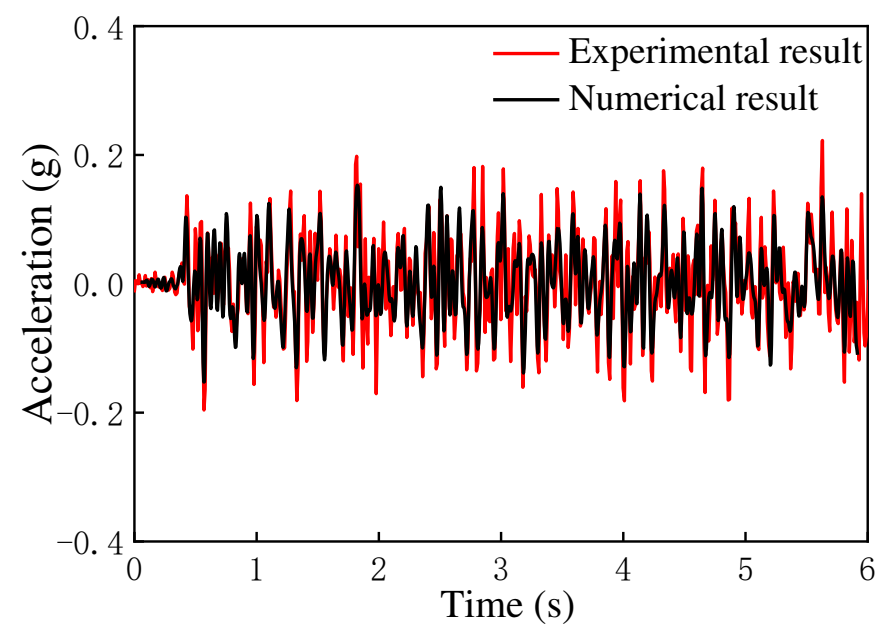

(b) Acceleration at the \#6 pier top

Fig. 8 Lateral structural responses under the earthquake action

3 The train influence on the seismic response of the track-bridge system for different pier heights 
In order to consider the influence of ground motion randomness, seismic waves were selected from the Pacific Earthquake Engineering Research Center (PEER) strong ground motion database by using the "Magnitude-distance bin approach" method(Jiang et al. 2020; Yu et al. 2021). The principle of seismic wave selection was as follows. With magnitude $\mathrm{M}=7$ considered as the limit between large and small earthquakes, and epicentral distance $\mathrm{R}=30 \mathrm{~km}$ taken as the boundary between near-field and far-field earthquakes, four different ground motion bins were distinguished, and 10 seismic waves were evenly distributed in each bin, with a total of 40 seismic waves, as shown in Table 5. In order to consider the 8 degree earthquake fortification zone, the amplitudes of ground motions were scaled to peak accelerations of frequent $(0.07 \mathrm{~g})$, moderate $(0.20 \mathrm{~g})$ and rare $(0.38 \mathrm{~g})$ earthquakes, while retaining the spectral characteristics and duration of the records. A total of 120 seismic excitations were obtained after amplitude scaling, and were considered for two conditions, with and without vehicles. The seismic response analysis of the track-bridge system was extracted, and 240 samples of its dynamic response were obtained.

Table 5 Ground motion bins

\begin{tabular}{|c|c|c|c|}
\hline Bin name & Epicenter range $(\mathrm{km})$ & Magnitude range & Number of seismic waves \\
\hline SRSM (small distance, small magnitude) & $10-30$ & $5-7$ & 10 \\
\hline LRLM (large distance, large magnitude) & $30-50$ & $7-9$ & 10 \\
\hline SRLM (small distance, large magnitude) & $10-30$ & $7-9$ & 10 \\
\hline LRSM (large distance, small magnitude) & $30-50$ & $5-7$ & 10 \\
\hline
\end{tabular}

In order to study the influence of the high-speed train on the seismic response of the track-bridge system with different pier heights, short, median and high pier types were selected for analysis (piers with heights of 4, 20, and $40 \mathrm{~m}$, respectively). A comparison of the seismic responses of short $(4 \mathrm{~m})$ piers with and without the train is shown in Fig. 9, whereas Fig. 10 and Fig. 11 show a comparison of the seismic responses of median $(20 \mathrm{~m})$ and high $(40 \mathrm{~m})$ piers with and without the train.

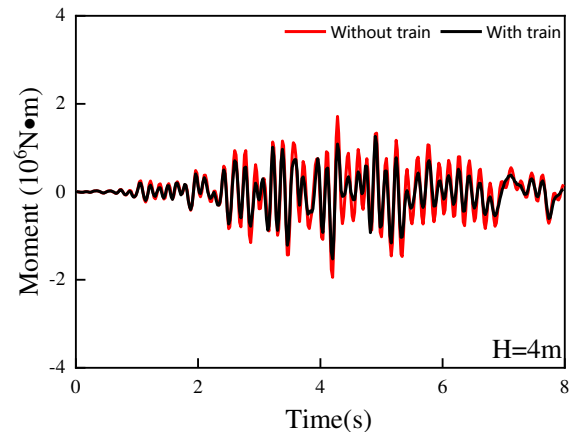

(a) Bending moment of the pier

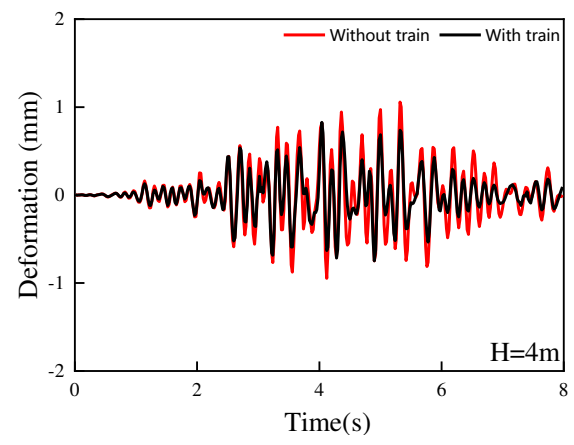

(d) Deformation of the sliding layer

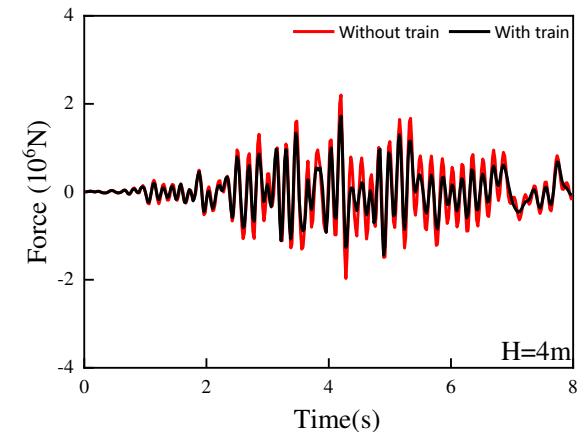

(b) Shear force of the pier

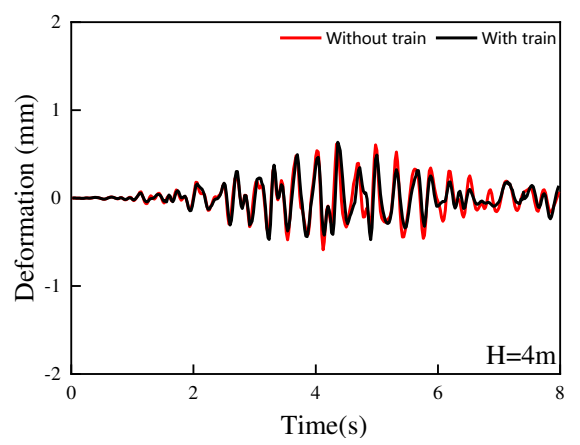

(e) Deformation of the mortar layer

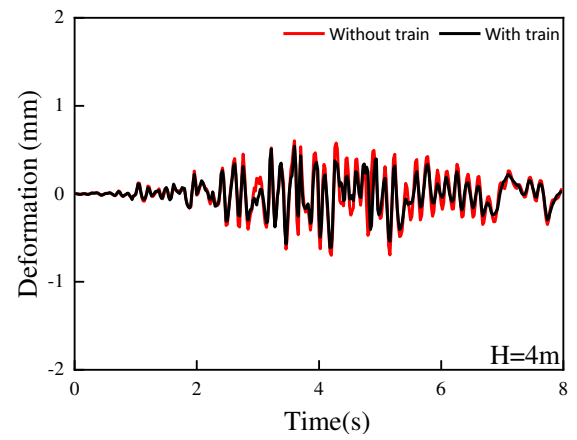

(c) Deformation of the fixed bearing

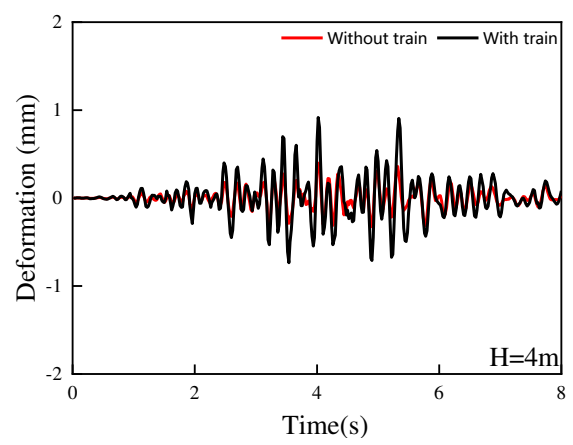

(f) Deformation of the fastener

Fig. 9 Lateral seismic responses of the structure with short (4 m) piers

As can be seen from Fig. 9, the pier bending moment, the shear force, and the deformation of the fixed bearing, were 
significantly reduced in the active condition (with train) compared with the non-active condition (without train), and the magnitude decrease was larger than $20 \%$; the seismic response reduction of the sliding layer and mortar layer was not obvious, with the decrease magnitude of only around $10 \%$; the deformation of the fastener significantly increased, even more than $300 \%$, which generally represents a serious threat to the track structure safety. It is because for a bridge structure a train crossing the bridge is increasing the superstructure mass and can increase the energy dissipation capacity of piers under an earthquake. The response of the track structure is affected by the deformation effect of the train itself and the inertial effect when the train crosses the bridge. The interlayer energy dissipation capacity of the track structure increases, while the impact force of the train also increases the track structure deformation.

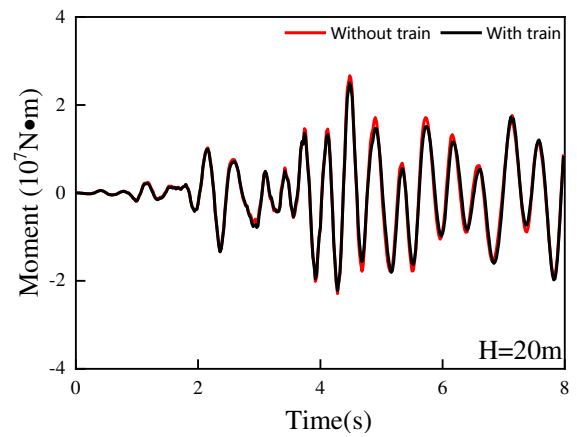

(a) Bending moment of the pier

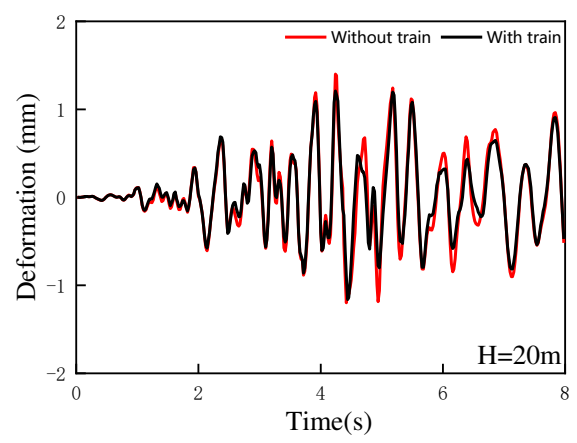

(d) Deformation of the sliding layer

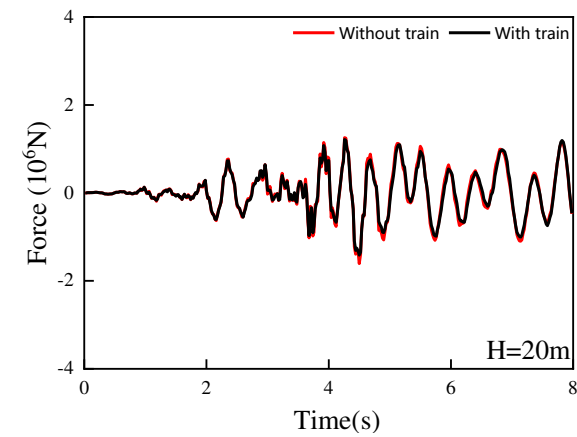

(b) Shear force of the pier

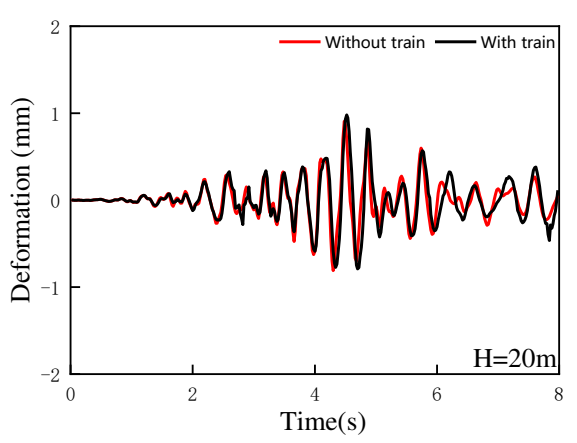

(e) Deformation of the mortar layer

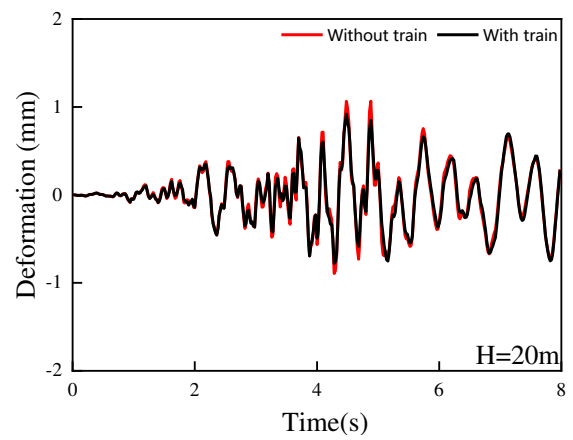

(c) Deformation of the fixed bearing

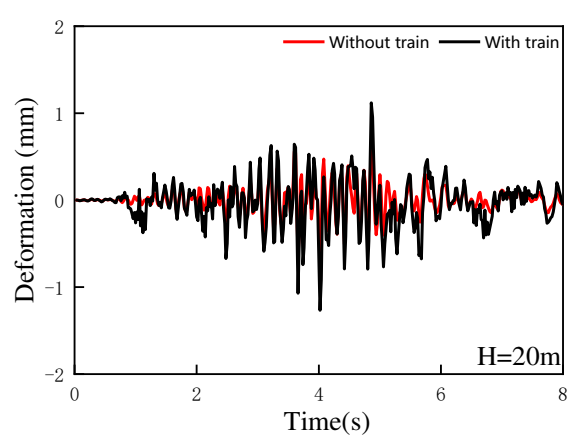

(f) Deformation of the fastener

Fig. 10 Lateral seismic responses of the structure with median $(20 \mathrm{~m})$ piers

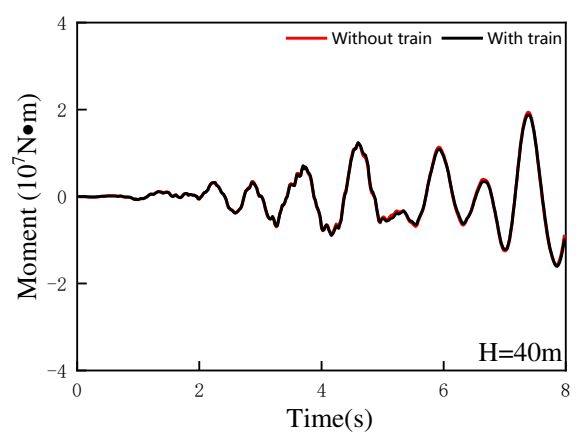

(a) Bending moment of the pier

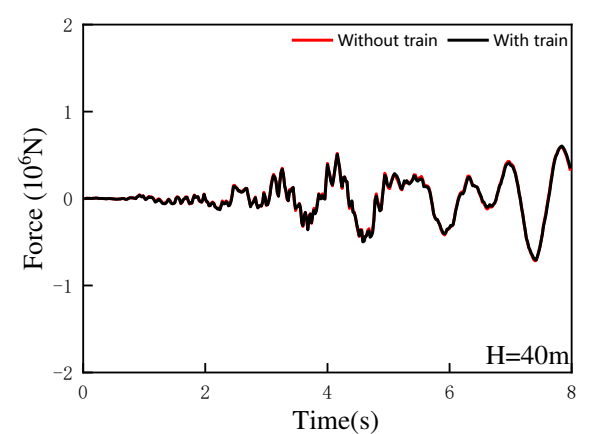

(b) Shear force of the pier

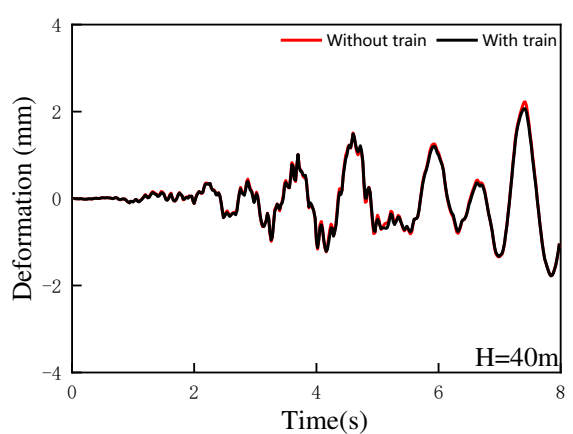

(c) Deformation of the fixed bearing 


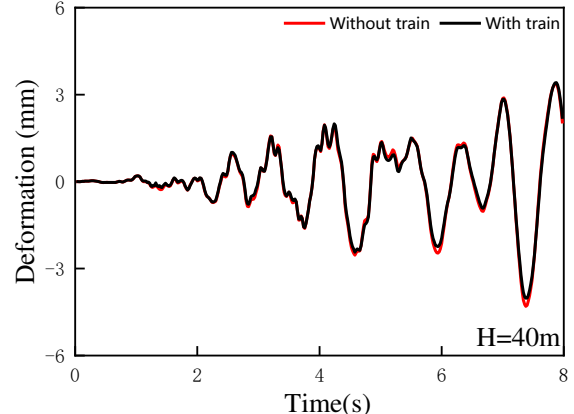

(d) Deformation of the sliding layer

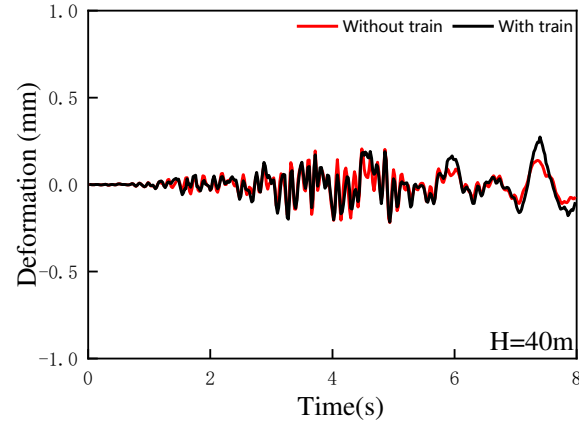

(e) Deformation of the mortar layer

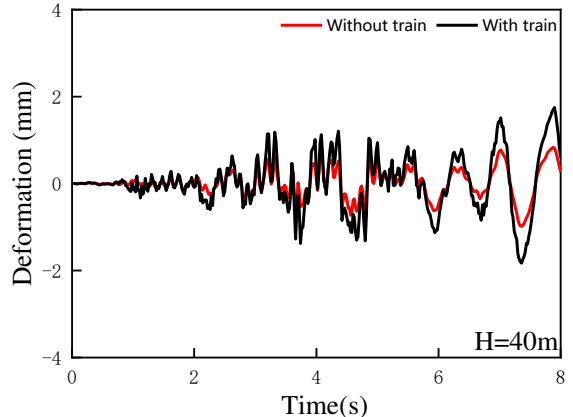

(f) Deformation of the fastener

Fig. 11 Lateral seismic responses of the structure with high $(40 \mathrm{~m})$ piers

By comparing Fig. 9 to Fig. 11, it can be seen that for different pier heights the train dynamic effectively reduced the bending moment, the shear force and the deformation of the fixed bearing, and when the pier height was $20 \mathrm{~m}$, the decrease level was around $10 \sim 15 \%$. However, the train dynamic effect on piers and supports decreased with the pier height increase, so when the pier height was $40 \mathrm{~m}$, the decrease level was only around 5 10\%. The train dynamic effect on the track structure had no obvious influence for different pier heights. The reason is that with the pier height increase the pier stiffness decreased, and the energy dissipation effect between track layers caused by trains also decreased. In order to further study the influence level of trains on the track-bridge system, the peak seismic response ratio $\delta$ of the track-bridge system under the condition of vehicle and no vehicle during an earthquake was chosen as the performance index reflecting the influence level of the train dynamic effect. The distribution of $\delta$ for different pier heights is shown in Fig. 12.

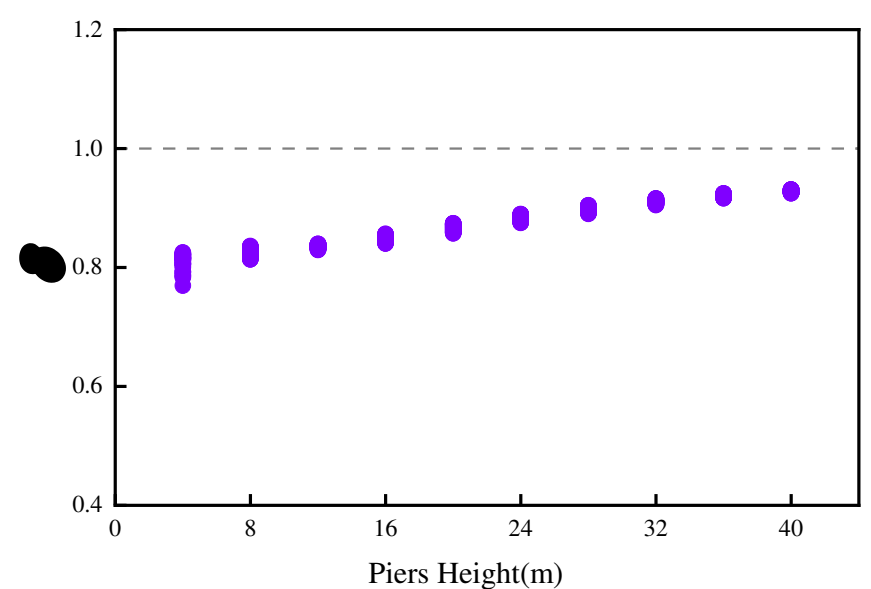

(a) Bending moment of the pier

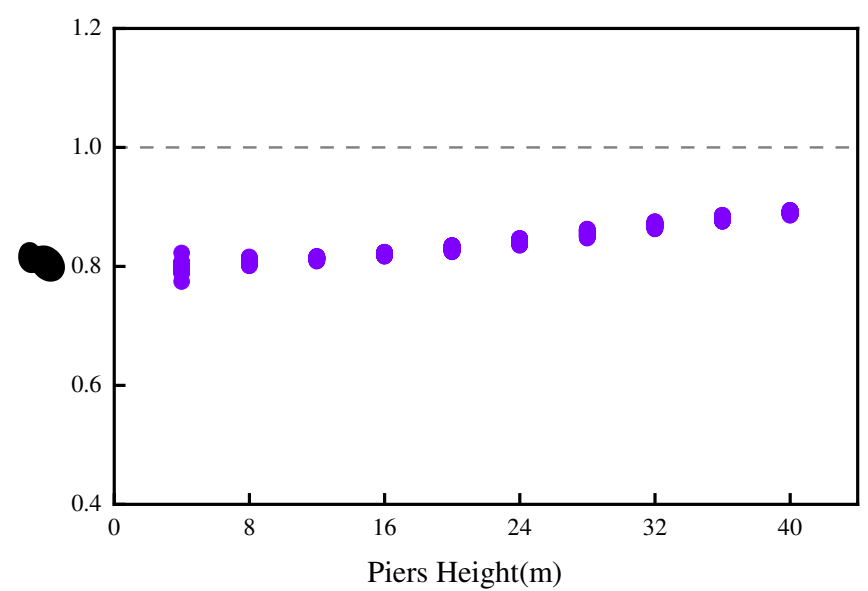

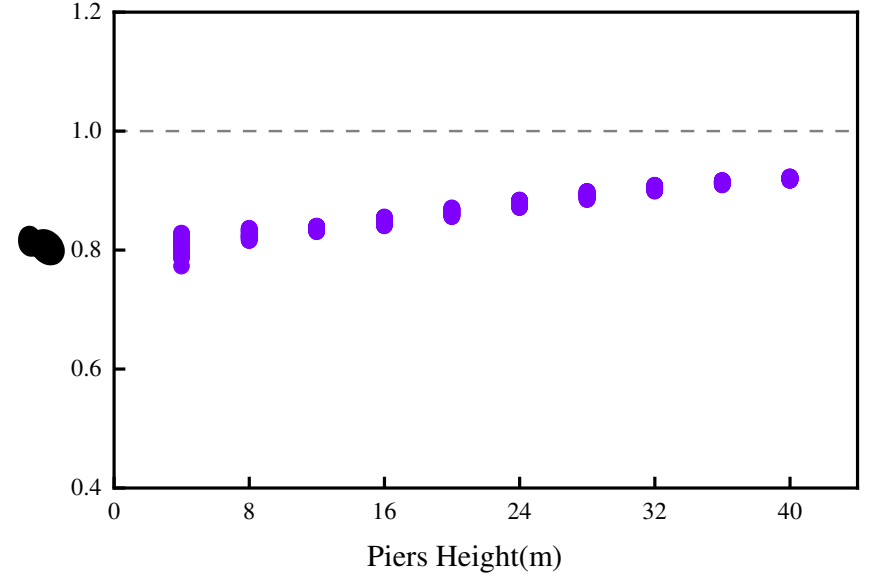

(b) Shear force of the pier

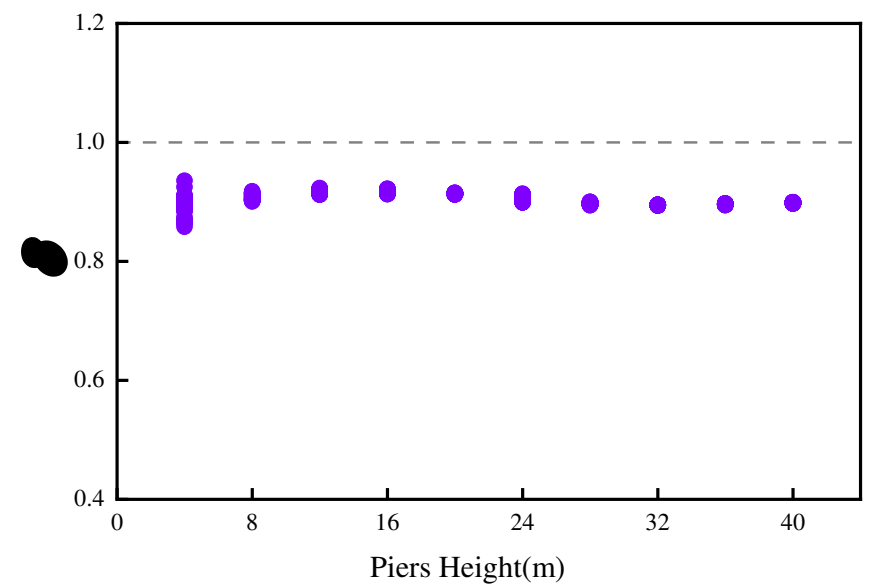


(c) Deformation of the fixed bearing

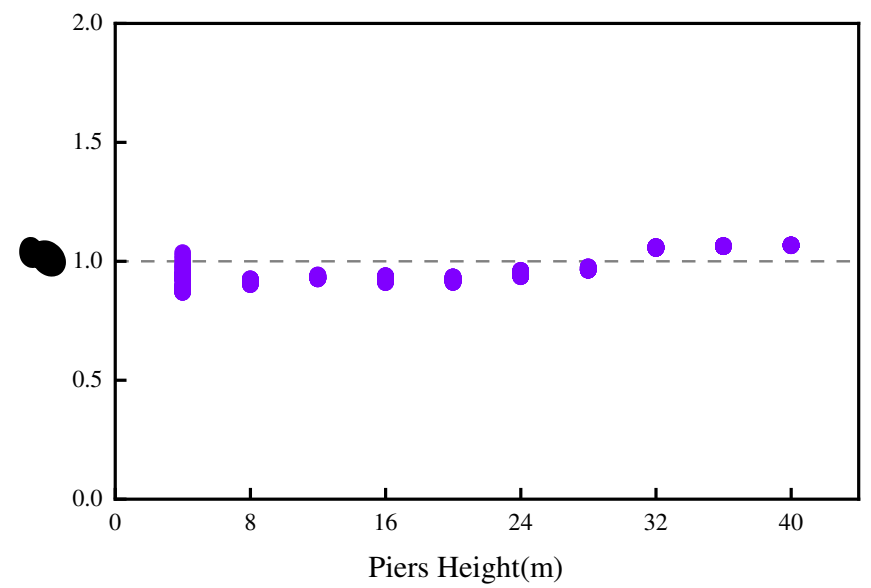

(e) Deformation of the mortar layer (d) Deformation of the sliding layer

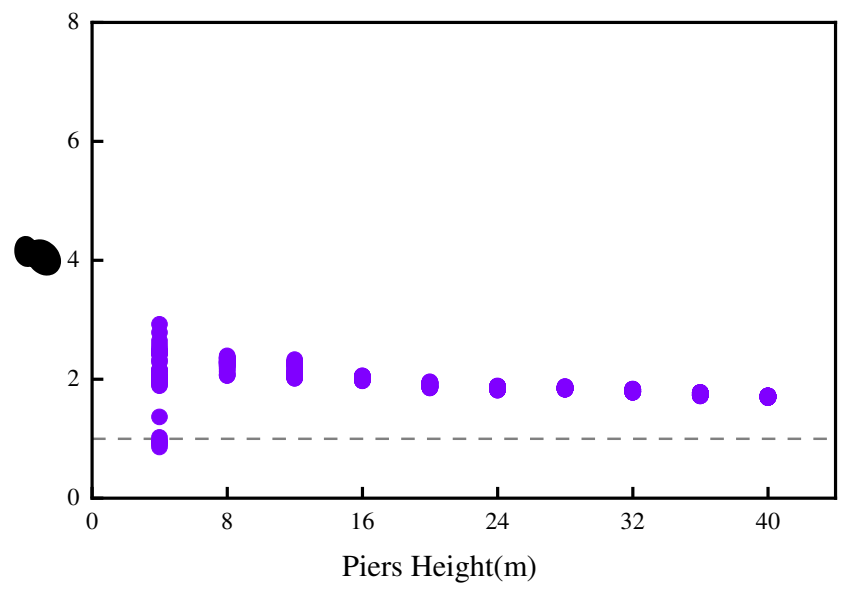

(f) Deformation of the fastener

Fig. 12 Scattered point distribution of $\delta$ for lateral seismic responses of the structure

As can be seen from Fig. 12, in scatter plots of the pier bending moment, shear force and bearing deformation, $\delta$ was relatively discrete for low pier heights, which proves that low piers were significantly affected by the vehicle dynamic effect. With the pier height increase, scattered $\delta$ points gradually moved towards the dotted line, the influence of the surface vehicle dynamic effect gradually decreased with pier height, but did not diminish. The scatter plots of the sliding layer, CA mortar layer and fastener, show that the dynamic effect of vehicle had no obvious influence on the seismic response of the track structure. The $\delta$ value of the fastener displacement was basically smaller than 1 , and decreased gradually with an increase in the pier height, but the decreasing rate was small, indicating that the train dynamic effect on the track structure was not significantly affected by the pier height.

\section{The train influence level on the seismic response of the track-bridge system for different pier heights}

\subsection{Probability distribution model of the train dynamic effect for the track-bridge system seismic response}

In order to determine whether the samples obey the normal distribution, Shapiro-Wilk (SW) test was adopted to calculate the statistical law, which is suitable for small sample size analysis (3 50 samples) (Shapiro and Wilk 1965; Mara 2011; Razali and Wah 2011). It was assumed that the number of seismic structural responses was $n$, and that the random samples corresponding to each earthquake were $\delta_{i}(i=1,2, \ldots, k)$. The data was rearranged in ascending order, so that $\delta_{1} \leq \delta_{2} \leq \delta_{3} \cdots \leq \delta_{\mathrm{n}-1} \leq \delta_{\mathrm{n}}$ :

$S^{2}$ was calculated as follows:

$$
S^{2}=\sum_{i=1}^{n}\left(\delta_{i}-\bar{\delta}\right)^{2}
$$

where $\bar{\delta}$ is the mean value of $\delta_{i}$, and $S^{2}$ denotes the usual symmetric unbiased estimate of $(n-1) \boldsymbol{\sigma}^{2}$, and

$$
\sigma=\frac{m^{\ell} V^{-1} \delta}{m^{c} V^{-1} m}
$$

It should be noted that $\mathbf{m}=\left(m_{1}, \ldots, m_{n}\right)^{\mathrm{T}}$ is the vector made of the expected values of the order statistics of independent 
and identically distributed random variables sampled from the standard normal distribution, and $\mathbf{V}$ is the covariance matrix of those normal order statistics.

The best linear unbiased estimate of the slope of a linear regression of the ordered observation, $b$, is defined as follows:

$$
b=\sum_{i=1}^{n} a_{i} \delta_{i}
$$

The coefficients $a_{i}$ are given by:

$$
\left(a_{1}, \ldots, a_{n}\right)=\frac{\mathbf{m}^{\mathbf{T}} \mathbf{V}^{-1}}{\mathbf{C}}
$$

where $\mathbf{C}$ is a vector norm: ${ }^{\mathrm{i}}$

$$
\mathbf{C}=\left\|\mathbf{V}^{-1} \mathbf{m}\right\|=\left(\mathbf{m}^{\mathbf{T}} \mathbf{V}^{-1} \mathbf{V}^{-1} \mathbf{m}\right)^{\frac{1}{2}}
$$

The statistical parameters obtained by the SW test were calculated as follows:

$$
W=\frac{b^{2}}{S_{w}}=\frac{\left(\sum_{i=1}^{n} a_{i} \delta_{i}\right)^{2}}{\sum_{i=1}^{n}\left(\delta_{i}-\bar{\delta}\right)^{2}}
$$

For a given value of $n$, the corresponding $P$ value was looked up in the Shapiro-Wilk Tables (Razali and Wah 2011; Field 2013). When $P$-value is greater than 0.05 , the statistic is normally distributed.(Field 2013) Thus, the statistic $R$ was specified as follows:

$$
R= \begin{cases}0, & P<0.05 \\ 1, & P \geq 0.05\end{cases}
$$

If $R=1$, then the data conforms to the normal distribution, i.e.

$$
\delta \sim N\left(\mu, \sigma^{2}\right)
$$

where $\mu$ and $\sigma$ represent the mean and variance of the population, respectively.

In order to judge whether the obtained sample represents the whole, according to the Khinchin's law of large numbers, for any given real number $\varepsilon>0$ the following condition should be met:

$$
\lim _{n \rightarrow \infty} P\left\{\left|\frac{1}{n} \sum_{i=1}^{n} \delta_{i}-\mu\right|<\varepsilon\right\}=1
$$

where $P$ is the probability that the sample mean corresponds to the population mean in the occurrence experiment. If $P$ approaches 1 , it can be theoretically demonstrated that the sample size is large enough and the sample mean gradually approximates the real population value, meaning that $\delta_{i}$ can be considered as having the same statistical characteristics as $\delta$.

If $\alpha$ represents the significance level, $\delta_{U}$ and $\delta_{L}$ represent upper and lower boundaries (respectively), then

$$
\begin{gathered}
P\left\{\delta_{\mathrm{L}} \leq \delta \leq \delta_{\mathrm{U}}\right\}=1-2 \alpha \\
P\left\{\frac{\delta_{\mathrm{L}}-\bar{\delta}}{s} \leq \frac{\delta-\mu}{\sigma}=\frac{\delta-\bar{\delta}}{s} \leq \frac{\delta_{\mathrm{U}}-\bar{\delta}}{s}\right\}=1-2 \alpha
\end{gathered}
$$


where $S$ is the standard deviation of the sample, and the values of $\delta_{U}$ and $\delta_{L}$ from Eqs. (10) and (11) are:

$$
\begin{aligned}
& \delta_{\mathrm{L}}=S z_{-\alpha}+\bar{\delta} \\
& \delta_{\mathrm{U}}=S z_{\alpha}+\bar{\delta}
\end{aligned}
$$

where $z$ is the quantile of the standard normal function.

Table $6 R$ values of the scattered $\delta$ points corresponding to different pier heights

\begin{tabular}{cccccccccccc}
\hline Category & \multicolumn{1}{c}{ Pier heights (m) } \\
& 4 & 8 & 12 & 16 & 20 & 24 & 28 & 32 & 36 & 40 \\
\hline$\delta$ of the fastener deformation & 1 & 1 & 1 & 1 & 1 & 1 & 1 & 1 & 1 & 1 \\
$\delta$ of the CA mortar layer deformation & 1 & 1 & 1 & 1 & 1 & 1 & 1 & 1 & 1 & 1 \\
$\delta$ of the sliding layer deformation & 1 & 1 & 1 & 1 & 1 & 1 & 1 & 1 & 1 & 1 \\
$\delta$ of the bearing deformation & 1 & 1 & 1 & 1 & 1 & 1 & 1 & 1 & 1 & 1 \\
$\delta$ of the pier shear force & 1 & 1 & 1 & 1 & 1 & 1 & 1 & 1 & 1 & 1 \\
$\delta$ of the pier bending moment & 1 & 1 & 1 & 1 & 1 & 1 & 1 & 1 & 1 & 1 \\
\hline
\end{tabular}

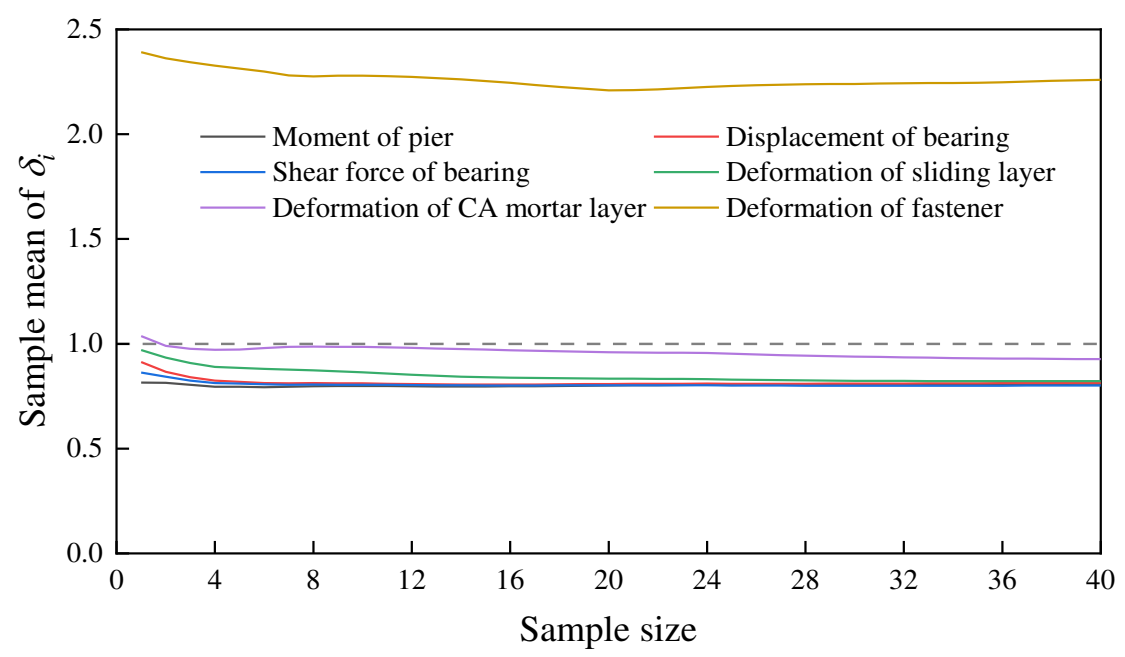

Fig. 13 Sample mean of $\delta$

The values of $R$ calculated according to Eqs. (1) to (7) are provided in Table 6, which shows that $\delta$ is normally distributed. The $P$ values obtained by Eqs. (8) and (9) approache 1 with the sample size increase, as shown in Fig. 14, which proves that the results tend to be stable and that the sample can represent the whole. Therefore, the sample $\delta_{i}(i=1,2, \ldots, k)$ can be used to predict the statistical characteristics of the population.

\subsection{Safety factor for different pier heights}

In China's current “Code for Seismic Design of Rail Engineering” (Ministry of Railways of People’s Republic of China, 2009), a train is represented by an additional mass on a main girder, and the seismic response of the bridge is calculated by considering the two working conditions, i.e. with and without the train. However, simulations based on the additional mass cannot accurately consider the real situation of the train loading, and there is a large deviation (Kim and Kawatani 2006; Kim et al. 2011 ; He et al. 2011), which makes it difficult to meet the high precision and requirements of the HSR construction. For $0.05 \alpha$, which can have a large enough guarantee rate (95\%), the calculated values of $\delta_{L}$ and $\delta_{U}$ for different pier heights are shown in Table 7. For a 
random earthquake, the ratio of a railway bridge seismic responses of the system under vehicle and no vehicle conditions basically falls between $\delta_{L}$ and $\delta_{U} \cdot \delta_{U}$, as the safety factor, is an upper limit, so the response under vehicle condition can be simplified as the response under no vehicle condition multiplied by $\delta_{U}$. The product has $95 \%$ reliability, which can effectively reduce the computational effort and the design difficulty of the track-bridge system.

Table 7 Safety factor reference table

\begin{tabular}{|c|c|c|c|c|c|c|c|}
\hline \multirow{2}{*}{\multicolumn{2}{|c|}{$\begin{array}{l}\text { Analysis index } \\
\text { Seismic level }\end{array}$}} & Fastener & CA mortar layer & Sliding layer & Bearing & Pier SF & Pier BM \\
\hline & & Frequent & Frequent & Frequent & Rare & Rare & Frequent \\
\hline \multirow{10}{*}{ Height } & 4 & $(1.79,1.88)$ & $(0.94,0.99)$ & $(0.76,0.77)$ & $(0.82,0.84)$ & $(0.95,0.97)$ & $(0.72,0.73)$ \\
\hline & 8 & $(1.76,1.78)$ & $(0.98,1.01)$ & $(0.76,0.77)$ & $(0.83,0.84)$ & $(0.97,0.98)$ & $(0.72,0.73)$ \\
\hline & 12 & $(1.64,1.66)$ & $(0.99,1.00)$ & $(0.78,0.79)$ & $(0.83,0.84)$ & $(0.96,0.97)$ & $(0.73,0.74)$ \\
\hline & 16 & $(1.57,1.58)$ & $(0.95,0.96)$ & $(0.94,0.102)$ & $(0.83,0.84)$ & $(0.95,0.96)$ & $(0.75,0.76)$ \\
\hline & 20 & $(1.48,1.50)$ & $(0.94,0.103)$ & $(0.79,0.81)$ & $(0.84,0.85)$ & $(0.95,0.96)$ & $(0.79,0.80)$ \\
\hline & 24 & $(1.46,1.48)$ & $(0.93,0.94)$ & $(0.81,0.82)$ & $(0.85,0.86)$ & $(0.95,0.96)$ & $(0.82,0.83)$ \\
\hline & 28 & $(1.47,1.48)$ & $(0.95,0.96)$ & $(0.82,0.83)$ & $(0.86,0.87)$ & $(0.95,0.96)$ & $(0.84,0.85)$ \\
\hline & 32 & $(1.44,1.45)$ & $(0.97,0.98)$ & $(0.82,0.83)$ & $(0.88,0.89)$ & $(0.95,0.96)$ & $(0.86,0.87)$ \\
\hline & 36 & $(1.39,1.40)$ & $(0.98,0.99)$ & $(0.83,0.84)$ & $(0.89,0.90)$ & $(0.96,0.97)$ & $(0.87,0.88)$ \\
\hline & 40 & $(1.35,1.36)$ & $(0.98,1.00)$ & $(0.83,0.84)$ & $(0.90,0.91)$ & $(0.96,0.97)$ & $(0.89,0.90)$ \\
\hline
\end{tabular}

SF represents the shear force; BM represent the bending moment.

\section{Conclusions}

In this study, a coupled vehicle-bridge finite element model with different pier heights was established and verified by the experiment, and the uncertainty of ground motions was examined. The train influence mechanism on the bridge structure response was analyzed under random earthquakes and for different pier heights. The following conclusions were obtained:

(1) Compared with the non-train working condition, the bending moment, shear force and the response of the bridge pier and support significantly decreased under the train working condition. The differences in the seismic responses of the sliding and mortar layers were not obvious, while the seismic response of fasteners increased significantly. The latter generally represents a serious threat to the track structure safety. The reason is that when a train passes over a bridge, the deformation effect of the train itself and the inertia effect increase the deformation of the track structure, improve its interlayer energy dissipation capacity, and reduce the seismic response of the bridge structure.

(2) For different pier heights, the train dynamic effect significantly reduced the bending moment, shear force and pier support seismic response. The train dynamic effect on piers and supports decreased with the pier height increase, while the train dynamic effect on the track structure had no obvious influence for different pier heights. The reason is that with the pier height increase the pier stiffness decreased, and the energy dissipation effect between track layers caused by trains decreased as well.

(3) The seismic response ratio of the track-bridge system with and without the train was basically maintained between $\delta_{L}$ and $\delta_{U}$. When calculating the seismic response of bridges with and without trains, the operating condition can be approximately simplified as the product of the seismic response of the bridge without the train and $\delta_{U}$, and the result has a guarantee rate of $95 \%$, thus effectively reducing the calculation workload and design complexity of track-bridge systems. 


\section{Declaration of competing interest}

The authors declare that they have no known competing financial interests or personal relationships that could have appeared to influence the work reported in this paper.

\section{Acknowledgement}

This study was financially supported by the National Natural Science Foundation of China (52078487, 51778630 and U1934207) and the Hunan Innovative Provincial Construction Project (2019RS3009).

\section{References:}

Chandramohan R, Baker JW, Deierlein GG (2016) Quantifying the Influence of Ground Motion Duration on Structural Collapse Capacity Using Spectrally Equivalent Records. Earthq Spectra 32:927-950. https://doi.org/10.1193/122813eqs298mr2

Chen L, Zhang N, Jiang L, et al (2014) Near-fault directivity pulse-like ground motion effect on high-speed railway bridge. J Cent South Univ 21:2425-2436. https://doi.org/10.1007/s11771-014-2196-9

Chen Z, Zhai W, Yin Q (2018) Analysis of structural stresses of tracks and vehicle dynamic responses in train-track-bridge system with pier settlement. Proc Inst Mech Eng Part F J Rail Rapid Transit 232:421-434. https://doi.org/10.1177/0954409716675001

Du XT, Xu YL, Xia H (2012) Dynamic interaction of bridge-train system under non-uniform seismic ground motion. Earthq Eng Struct Dyn 41:139-157. https://doi.org/10.1002/eqe.1122

Field A (2013) Discovering Statistics Using IBM SPSS Statistics, 4th Edition

Frýba L (1996) DYNAMICS OF RAILWAY BRIDGES. Thomas Telford Publishing

Galton D (1850) Report of the commissioners appointed to inquire into the application of iron to railway structures. J Frankl Inst 49:289-302. https://doi.org/10.1016/0016-0032(50)90045-7

Guo W, Hu Y, Gou H, et al (2020) Simplified seismic model of CRTS II ballastless track structure on high-speed railway bridges in China. Eng Struct 211:110453. https://doi.org/10.1016/j.engstruct.2020.110453

Hancock J, Bommer JJ (2006) A State-of-Knowledge Review of the Influence of Strong-Motion Duration on Structural Damage. Earthq Spectra 22:827-845. https://doi.org/10.1193/1.2220576

He X, Kawatani M, Hayashikawa T, Matsumoto T (2011) Numerical analysis on seismic response of Shinkansen bridge-train interaction system under moderate earthquakes. Earthq Eng Eng Vib 10:85-97. https://doi.org/10.1007/s11803-011-0049-1

Jiang L, Yu J, Zhou W, et al (2020) Applicability analysis of high-speed railway system under the action of near-fault ground motion. Soil Dyn Earthq Eng 139:106289. https://doi.org/10.1016/j.soildyn.2020.106289

Kim C-W, Kawatani M (2006) Effect of train dynamics on seismic response of steel monorail bridges under moderate ground motion. Earthq Eng Struct Dyn 35:1225-1245. https://doi.org/10.1002/eqe.580

Kim SJ, Holub CJ, Elnashai AS (2011) Analytical Assessment of the Effect of Vertical Earthquake Motion on RC Bridge Piers. J Struct Eng 137:252-260. https://doi.org/10.1061/(ASCE)ST.1943-541X.0000306

Liu Z, Jiang H, Zhang L, Guo E (2018) Natural Vibration Characteristics and Seismic Response Analysis of Train-Bridge Coupling System in High-Speed Railway. In: Conte JP, Astroza R, Benzoni G, et al. (eds) Experimental Vibration Analysis for Civil Structures. Springer International Publishing, Cham, pp 831-838

Mackie K, Stojadinović B (2001) Probabilistic Seismic Demand Model for California Highway Bridges. J Bridge Eng 6:468-481. https://doi.org/10.1061/(ASCE)1084-0702(2001)6:6(468)

Mara UT (2011) Power Comparisons of Shapiro-Wilk, Kolmogorov-Smirnov, Lilliefors and Anderson-Darling Tests. 13

Raghunandan M, Liel AB (2013) Effect of ground motion duration on earthquake-induced structural collapse. Struct Saf 41:119- 
133. https://doi.org/10.1016/j.strusafe.2012.12.002

Razali NM, Wah YB (2011) Power comparisons of Shapiro-Wilk, Kolmogorov-Smirnov, Lilliefors and Anderson-Darling tests. 14

Shapiro SS, Wilk MB (1965) An Analysis of Variance Test for Normality (Complete Samples). Biometrika 52:591. https://doi.org/10.2307/2333709

Su M, Dai G, Marx S, et al (2019) A Brief Review of Developments and Challenges for High-speed Rail Bridges in China and Germany. Struct Eng Int 29:160-166. https://doi.org/10.1080/10168664.2018.1456892

Tanabe M, Sogabe M, Wakui H, et al (2016) Exact Time Integration for Dynamic Interaction of High-Speed Train and Railway Structure Including Derailment During an Earthquake. J Comput Nonlinear Dyn 11:031004. https://doi.org/10.1115/1.4030829

Tanabe M, Wakui H, Sogabe M, et al (2011) An efficient numerical model for dynamic interaction of high speed train and railway structure including post-derailment during an earthquake. 7

The State Council Information Office of the People's Republic of China (2020) Sustainable development of transportation in China. Peoples Dly. 010

Timoshenko SP (1922) CV. On the forced vibrations of bridges. Lond Edinb Dublin Philos Mag J Sci 43:1018-1019. https://doi.org/10.1080/14786442208633953

Xia H, Guo WW, Wu X, et al (2008) Lateral dynamic interaction analysis of a train-girder-pier system. J Sound Vib 16

Yang, Wu (2002) DYNAMIC STABILITY OF TRAINS MOVING OVER BRIDGES SHAKEN BY EARTHQUAKES. J Sound Vib 258:65-94. https://doi.org/10.1006/jsvi.2002.5089

Yang Y-B, Yau J-D (1997) Vehicle-Bridge Interaction Element for Dynamic Analysis. J Struct Eng 123:1512-1518. https://doi.org/10.1061/(ASCE)0733-9445(1997)123:11(1512)

Yu J, Jiang L, Zhou W, et al (2020) Study on the dynamic response correction factor of a coupled high-speed train-track-bridge system under near-fault earthquakes. Mech Based Des Struct Mach 1-19. https://doi.org/10.1080/15397734.2020.1803753

Yu J, Jiang L, Zhou W, et al (2021) Study on the influence of trains on the seismic response of high-speed railway structure under lateral uncertain earthquakes. Bull Earthq Eng. https://doi.org/10.1007/s10518-021-01085-1

Zeng Z-P, Zhao Y-G, Xu W-T, et al (2015) Random vibration analysis of train-bridge under track irregularities and traveling seismic waves using train-slab track-bridge interaction model. J Sound Vib 342:22-43. https://doi.org/10.1016/j.jsv.2015.01.004 